\title{
Paraplegia
}

\section{Body Composition and Resting Energy Expenditure in Long Term Spinal Cord Injury}

\author{
D. A. Sedlock, PhD, S. J. Laventure, MS \\ Exercise Physiology Laboratory, Purdue University, West Lafayette, Indiana 47907, \\ USA.
}

\begin{abstract}
Summary
Body composition and resting metabolic rate $(R M R)$ were measured in 4 spinal cord injured (SCI) paraplegic men. The level of lesion ranged from T4 to L1, and the duration of disability averaged $7 \cdot 4 \pm 3 \cdot 3$ (SEM) years. Hydrodensitometry was used to determine percent body fat, fat mass and lean body mass (LBM). RMR was measured following a 12-hour fast and 24 hours post-exercise using a ventilated hood. RMR was also predicted from LBM values based on the equation of Cunningham (1980). Results of the body composition measurements indicated a greater than average amount of body fat for men of this age group. RMR and LBM were significantly correlated $(r=0.98$, $p<0.02$ ). However, measured RMR values were lower than predicted in 3 of the 4 subjects, especially when LBM was relatively low. Further investigation into the relationship between LBM and RMR in SCI individuals is warranted using a larger sample size and with subjects representing a wide range of lesion level.
\end{abstract}

Key words: Spinal cord injury; Paraplegia; Resting metabolic rate; Body composition.

Results of extensive epidemiological research have led to the identification of several factors which increase the risk of developing coronary heart disease. One of these factors is obesity (Hubert et al., 1983). Increased levels of stored body fat are the result of a positive energy balance, which occurs when energy intake exceeds energy expenditure. Whereas energy intake is dependent on food ingestion, the major components of energy expenditure include resting metabolic rate (RMR), dietary induced thermogenesis, and physical activity. Recent evidence shows that, in many cases, increasing levels of body fat are more closely related to decreases in energy expenditure rather than to increased energy intake (Keen et al., 1979; Stunkard and Penick, 1979).

In sedentary populations, RMR is the greatest contributor to energy expenditure, estimated by some to account for up to $80 \%$ of the total daily energy requirement (Tremblay et al., 1985). Because of the extremely sedentary lifestyle of spinal cord 
injured (SCI) and other lower body disabled individuals, they tend to exhibit higher than average values of body fat and are at greater risk for developing cardiovascular disease (Cowell et al., 1986; Rose et al., 1987). For these individuals, RMR is of critical importance to their energy balance, weight regulation, and long term health status.

RMR has been shown to be significantly correlated with several indices of body size or mass, such as body weight, body surface area, and lean body mass (LBM). Of these, the best singular predictor of resting energy expenditure is LBM (Tzankoff and Norris, 1978; Ravussin et al., 1982; Segal et al., 1985). Given that many lower body disabled individuals, especially paraplegics, show some degree of skeletal muscle atrophy in the affected areas, it is possible that this diminished LBM may be reflected in a lower RMR. However, few studies have examined the resting energy expenditure of SCI individuals (Cooper et al., 1950; Clarke, 1966; Mollinger et al., 1985). Results of these studies are inconsistent regarding the possibility of a reduced RMR. Moreover, RMR is expressed in these studies either in absolute terms, or relative to body weight or body surface area. To our knowledge, there is no literature which examines the resting energy expenditure of SCI individuals relative to their body composition. Therefore, the purpose of this study was to examine the body composition and RMR of individuals with long-standing paraplegia.

\section{Methods}

\section{Subjects}

Four young adult males with a mean ( \pm SEM) age of $27 \cdot 7 \pm 2 \cdot 3$ years and selfreported height of $180.5 \pm 2.5 \mathrm{~cm}$ volunteered for the study. All were paraplegics with a level of spinal cord lesion ranging from $\mathrm{T} 4$ to $\mathrm{L} 1$ and a mean duration of $7 \cdot 4 \pm 3 \cdot 3$ years of disability. They were free from decubitus ulcers and were otherwise healthy during the study period. The procedures used in this study were reviewed and approved by the institutional committee for research involving human subjects. All subjects acknowledged understanding the nature of the study, the extent of their participation and their rights as subjects by signing a statement of informed consent.

\section{Body composition}

Body density was determined using the hydrostatic weighing technique, with residual lung volume measured by oxygen dilution (Wilmore et al., 1980). Body density was converted to percent body fat using the equation of Siri (1956), and LBM was calculated by subtracting fat mass from total body weight.

\section{Resting metabolic rate}

RMR was measured between 07:00 and 08:00 following a 12-hour fast and a minimum of 24 hours post-exercise. Subjects lay supine on a standard hospital bed for 1 hour while oxygen uptake $\left(\dot{\mathrm{VO}}_{2}\right)$ and carbon dioxide production $\left(\dot{\mathrm{VCO}}_{2}\right)$ were measured by indirect calorimetry using a ventilated hood apparatus 
(SensorMedics Horizon System, Annaheim, CA). The first 30 minutes were considered an adaptation period, and the average of the minute values for $\mathrm{VO}_{2}$ obtained during the last 30 minutes was calculated as RMR. RMR was converted to caloric expenditure from $\mathrm{VO}_{2}$ and $\mathrm{VCO}_{2}$ measurements using the Weir formula (1949). Additionally, RMR for each subject was predicted from LBM based on the following equation (Cunningham, 1980):

$$
\operatorname{RMR}(\mathrm{Kcal} / \text { day })=501 \cdot 6+21 \cdot 6(\mathrm{Kg} \mathrm{LBM})
$$

\section{Results}

Body composition

Table I Mean ( \pm SEM) values for body composition of the subjects

\begin{tabular}{lcl}
\hline Variable & $\overline{\mathrm{X}}$ & SEM \\
\hline Weight $(\mathrm{Kg})$ & $73 \cdot 3$ & $4 \cdot 9$ \\
Body density (gm/cc) & $1 \cdot 047$ & $0 \cdot 006$ \\
Relative fat $(\%)$ & $23 \cdot 0$ & $2 \cdot 7$ \\
Fat mass $(\mathrm{Kg})$ & $17 \cdot 1$ & $2 \cdot 8$ \\
Lean body mass $(\mathrm{Kg})$ & $56 \cdot 3$ & $3 \cdot 5$ \\
\hline
\end{tabular}

The body composition values are shown in Table I. Results show that the subjects were of average body weight; however, relative fat values were higher than the average for this age group.

\section{Resting energy expenditure}

Table II Mean ( \pm SEM) values for resting energy expenditure of the subjects

\begin{tabular}{lcr}
\hline Variable & $\overline{\mathrm{X}}$ & SEM \\
\hline Oxygen uptake (L/minute) & $0 \cdot 22$ & 0.03 \\
Respiratory exchange ratio & 0.80 & 0.04 \\
Resting energy expenditure & & \\
$\quad(\mathrm{Kcal} /$ hour/Kg) & 0.87 & 0.06 \\
$\quad(\mathrm{Kcal} /$ hour/Kg LBM) & $1 \cdot 12$ & 0.06 \\
$\quad($ Kcal/day) & 1530 & 165 \\
Resting energy expenditure & & \\
predicted from Cunningham (1980) & & 75 \\
$\quad$ (Kcal/day) & 1718 & \\
\hline
\end{tabular}

Table II and the Figure show values for actual and predicted resting energy expenditure. Absolute values for $\mathrm{RMR}$ ( $\mathrm{Kcal} / \mathrm{minute}$ or $\mathrm{Kcal} / \mathrm{day})$ were significantly correlated with LBM in the SCI subjects $(r=0.98, p<0.02)$. However, these 


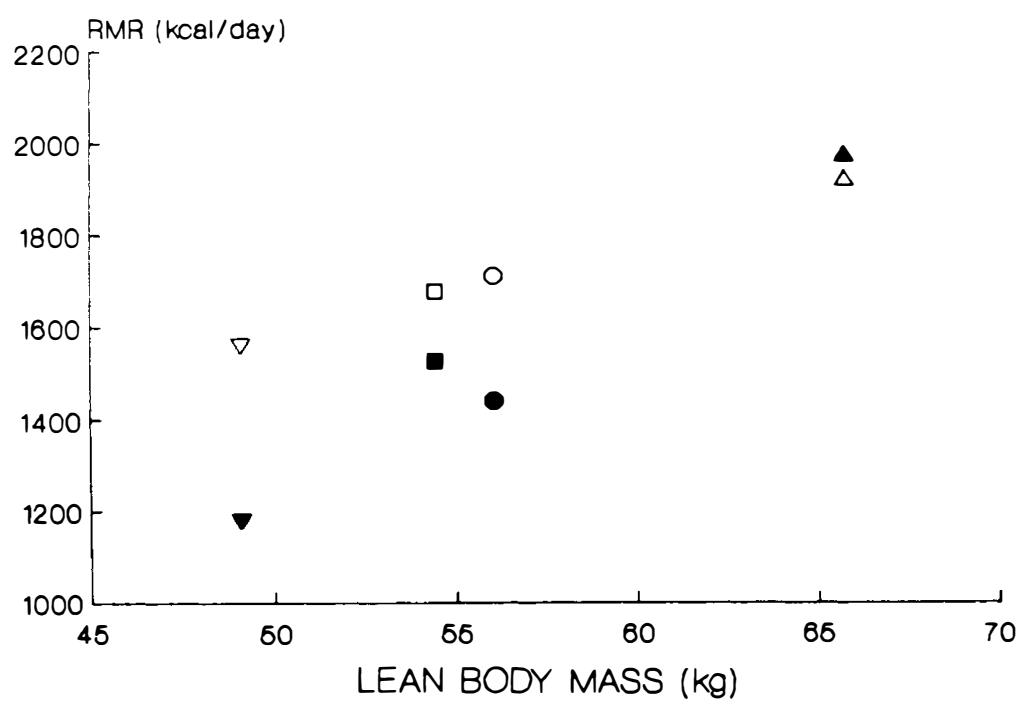

Figure Relationship between lean body mass and both actual (filled symbols) and predicted (open symbols) resting metabolic rate (RMR) for the subjects. Predicted values were calculated using the equation of Cunningham (1980).

values were substantially lower than the predicted RMR in 3 of the 4 subjects, as can be seen in the Figure. The percentage difference between actual and predicted RMR values for the subjects were $24 \%, 16 \%, 9 \%$ and $-3 \%$.

\section{Discussion}

This study was designed to investigate the relationship between body composition and RMR in a group of SCI men. Although some authors have reported resting and/or basal metabolic rates for various groups of wheelchair-dependent persons (Cooper et al., 1950; Clarke, 1966; Mollinger et al., 1985), none have examined this relationship according to body composition measurements. Our results showed a significant relationship to exist between RMR and LBM for the subjects of this study. These results should be interpreted cautiously, however, due to the limited sample size.

Hydrostatic weighing is currently the most widely accepted standard for determining body composition. In order for this technique to be valid, several assumptions must be met, including those pertaining to the constancy of the density of lean tissue. One might question the validity of applying this measurement technique to a group of SCI individuals, given the changes that occur in the composition of the tissue in the affected limbs (Cowell et al., 1986). However, nearly identical values for percent fat have been reported for densitometry and potassium $40\left({ }^{40} \mathrm{~K}\right)$ measurements in paraplegic women (Lussier et al., 1983). Additionally, Bulbulian et al. (1987) have suggested that prediction of body composition in paraplegics by hydrostatic weighing, in combination with the use of the equation of Siri (1956) for converting density to percent fat, seems to result in values that are within the expected range of error for this technique. Therefore, 
this method of determining body composition was chosen for the study.

Results of the body composition analysis indicated that our subjects were not necessarily overweight, but had a relatively high body fat content (Table I). Given that the average body fat value for able-bodied ( $\mathrm{AB}$ ) men of this age group is approximately $15 \%$ (McArdle et al., 1986), the mean value of $23 \%$ is indicative of a surplus of stored energy. In this regard, our results compare favourably with those of Rose et al. (1987) who reported relative body fat values of 23.2 and $22.6 \%$ for bilateral above the knee amputee and unilateral below the elbow amputee combat veterans, respectively.

The correlation of $r=0.98$ found between RMR and LBM in the SCI men was relatively high, and may have been partially influenced by sampling. However, the results indicate that, similar to the $A B$ population, RMR seems to be significantly related to LBM in low level paraplegics. These results could be expected based upon the factors that are known to contribute to RMR. That is, the majority of energy expended during rest can be accounted for by the relatively high metabolic activity of the viscera, with skeletal muscle accounting for only about $17 \%$ of the total energy expenditure (Bray and Atkinson, 1977). Since the tissue atrophy that occurs consequent to low level spinal cord transection involves mostly skeletal muscle, it follows that a high correlation should exist between RMR and LBM in these individuals.

An examination of Table II and the Figure indicates that although a significant relationship between RMR and LBM has been shown to exist for our subjects, actual RMR was lower than what was predicted from LBM values, particularly when LBM was relatively low. In other words, those individuals with low LBM values tended to show a more suppressed RMR than those men with a higher LBM component. It is possible that this altered relationship between RMR and LBM in SCI individuals might be influenced by the level of the spinal cord lesion. Mollinger et al. (1985) found a significant inverse correlation between level of lesion and basal metabolic rate in post-acute SCI individuals who were divided into 4 groups based on their level of lesion: high quadriplegia (C6 or higher), low quadriplegia (C6-T1), high paraplegia (T1-T10) and low paraplegia (T10 or below). Although the range of lesion level and number of subjects in the present study were too small to perform this type of analysis, it is interesting to note that the lowest value for RMR was found in the subject with the highest level of lesion (T4). This subject also had the least amount of LBM and was the only one of the 4 subjects who would be classified as high paraplegia according to Mollinger et al. (1985), the remaining subjects being of low paraplegia. In this regard, our data tend to support the findings of Mollinger et al. (1985).

The relationship between RMR and LBM could be affected by spinal cord transection if the lesion was at a level that would influence the integrity and metabolic activity of tissues that contribute to the majority of the resting energy expenditure. In paraplegia, for example, if the lesion was between $\mathrm{T} 1$ and $\mathrm{T} 10$ (as in the classification of high paraplegia), the affected areas would include the intercostal and thoracic muscles, abdominal muscles, part of the gastrointestinal tract, as well as the kidneys (Glaser, 1985). However, a lesion below this level would affect predominantly lower extremity skeletal muscle, which contributes little to resting energy expenditure. Therefore, as the level of lesion in the spinal cord becomes higher, greater amounts of muscle tissue are subjected to inactivity 
and subsequent atrophy (which will decrease the quantity of LBM of the individual). Moreover, a higher level of lesion will affect the metabolic activity of more of the organic tissues that are major contributors to RMR. All of these factors could influence LBM and RMR in the SCI population in a way that would make this relationship different than what would be found in the $A B$ population. Future investigations should be directed towards a further exploration of the relationship between RMR and LBM in individuals with a wide range in the level of spinal cord lesion.

This study was an initial attempt to investigate the relationship between RMR and LBM in paraplegics. Despite a limited sample size, our results show that there was a significant correlation between RMR and LBM in the SCI subjects. However, the relationship between these two variables seems to differ from predicted values based on data obtained from the $\mathrm{AB}$ population. Further investigation in this area using a larger sample size is warranted, especially with subjects representing a wide range of lesion level.

\section{References}

BRAy GA, AtKInSON RC 1977 Factors affecting basal metabolic rate. Progress in Food and Nutritial Science 2:385-403.

Bulbulian R, Johnson RE, Gruber JJ, Darabos B 1987 Body composition in paraplegic male athletes. Medicine and Science in Sports and Exercise 19:195-201.

ClARKE KS 1966 Calorie costs of activity in paraplegic persons. Archives of Physical Medicine and Rehabilitation 47:427-435.

CoOper IS, Rynearson EH, MacCarty CS, Power MH 1950 Metabolic consequences of spinal cord injury. Fournal of Clinical Endorcinology 10:858-870.

Cowell LL, SQuires WG, RAVEN PB 1986 Benefits of aerobic exercise for the paraplegic: a brief review. Medicine and Science in Sports and Exercise 18:501-508.

CUNNINGHAM JJ 1980 A reanalysis of the factors influencing basal metabolic rate in normal adults. American fournal of Clinical Nutrition 33:2372-2374.

GLASER RM 1985 Exercise and locomotion for the spinal cord injured. In: R J Terjung (ed) Exercise and Sport Sciences Reviews, vol 13. Macmillan, New York, pp 263-303.

Hubert HA, Feinleib, M, MCNamara PM, CASTelli WP 1983 Obesity as an independent risk factor for cardiovascular disease. A 26-year follow-up of participants in the Framingham heart study. Circulation 67:968-977.

KeEn H, Thomas BJ, Jarrett RJ, Fuller JH 1979 Nutrient intake, adiposity, and diabetes. British Medical fournal 1:655-658.

Lussier L, KNight J, Bell G, Lohman T, MorRis AF 1983 Body composition comparison in two elite female wheelchair athletes. Paraplegia 21:16-22.

McARdle WD, Katch FI, Katch VL 1986 Exercise Physiology: Energy, Nutrition, and Human Performance, 2nd edn. Lea \& Febiger, Philadelphia, p 507.

Mollinger LA, SPURr GB, El Ghatit AZ et al. 1985 Daily energy expenditure and basal metabolic rates of patients with spinal cord injury. Archives of Physical Medicine and Rehabilitation 66:420 426.

Ravussin E, Burnand B, Schutz Y, Jequier E 1982 Twenty-four hour energy expenditure and resting metabolic rate in obese, moderately obese, and control subjects. American fournal of Clinical Nutrition 35:566-573.

Rose HG, Schweitzer P, Charoenkul V, Schwartz E 1987 Cardiovascular disease risk factors in combat veterans after traumatic leg amputations. Archives of Physical Medicine and Rehabilitation 68:20-23.

Segal KR, Gutin B, Nyman AM, Pi-Sunyer FX 1985 Thermic effect of food at rest, during exercise, and after exercise in lean and obese men of similar body weight. Fournal of Clinical Investigation 76:1107-1112.

SIRI WE 1956 The gross composition of the body. Advances in Biological and Medical Physics 4:239280.

StUnKaRd AJ, Penick SB 1979 Behavior modification in the treatment of obesity: The problem of maintaining weight loss. Archives of General Psychology 36:801-806. 
Tremblay A, Despres J-P, Bouchard C 1985 The effects of exercise-training on energy balance and adipose tissue morphology and metabolism. Sports Medicine 2:223-233.

TZANKOFF SP, NoRRIS AH 1978 Longitudinal changes in basal metabolism in man. Fournal of Applied Physiology: Respiratory, Environmental and Exercise Physiology 45:536-539.

WEIR JB 1949 New methods for calculating metabolic rate with special reference to protein metabolism. Fournal of Physiology 109:1-9.

Wilmore JH, Vodak PA, PARR RB, Girandola RN, Billing JE 1980 Further simplification of a method for determination of residual lung volume. Medicine and Science in Sports and Exercise 12:216-218. 